\title{
El pragmatismo ambiental: una propuesta ética ambiental frente al cambio climático ${ }^{1}$
}

\section{Environmental Pragmatism: An Environmental Ethics Proposal Facing Climate Change}

\author{
Víctor Hugo Salazar Ortiz \\ Universidad Autónoma de Aguascalientes | México \\ Contacto:vhsalaza@correo.uaa.mx
}

\section{Resumen}

Este artículo se divide en tres partes. En la primera se revisa cuál es el origen de la ética ambiental y cómo se fue ampliando para conseguir una transición de la acotada visión antropocéntrica hacia una más amplia que integrara en sus criterios axiológicos a todos los seres vivos (éticas biocéntricas) y a los ecosistemas (éticas ecocéntricas), además desde ópticas muy particulares como la de la Ecología profunda y el ecofeminismo. Posteriormente, revisaremos cómo surge el pragmatismo ambiental, resultado de un trabajo crítico respecto al poco alcance social y político de la ética ambiental en sus primeras dos décadas. En la segunda parte se revisa el origen del estudio del cambio climático, el negacionismo climático y el impacto de los combustibles fósiles en el medio ambiente, ante lo cual se propone emplear los criterios del pragmatismo ambiental para frenar su incremento. En la tercera parte se comenta el pobre avance que se ha tenido en las cumbres climáticas para frenar el cambio climático y cómo este objetivo debe convertirse en la base para la construcción de un bien público.

Palabras clave: ética ambiental, pragmatismo ambiental, cambio climático, bien público

${ }^{1}$ Este trabajo forma parte del Proyecto de Investigación PIFI2020-1 "La inserción de la ética ambiental en la política pública” con el apoyo de la Universidad Autónoma de Aguascalientes. 


\begin{abstract}
This article is divided into three sections. In the first one, we review the origin of environmental ethics and how it was expanded to achieve a transition from the limited anthropocentric vision to a broader one that integrated all living things (biocentric ethics) and ecosystems (ecocentric ethics) into its axiological criteria, also from very particular perspectives such as deep ecology and ecofeminism. Subsequently, we review how environmental pragmatism arises, the result of critical work regarding what happened with the little social and political impact of environmental ethics in its first two decades. In the second part, the origin of the study of climate change, climate denialism and the impact of fossil fuels on the Environment is reviewed, and then it is proposed to use the criteria of environmental pragmatism to stop its increase. In the third section, the poor progress made in the Climate Summits to curb climate change is discussed and how this objective should become the basis for the construction of a public good.
\end{abstract}

Keywords: environmental ethics, environmental pragmatism, climate change, public good

\title{
Ética ambiental y pragmatismo ambiental
}

El área filosófica más importante para abordar el tema del cambio climático es la ética, específicamente, la ética ambiental. Este campo de estudio se originó en la década de 1970 con la intención de evaluar la conducta moral hacia el medio ambiente. El análisis comenzó con una dura crítica al patrón antropocentrista vigente, mismo que estaba asentado en toda una tradición religiosa, filosófica y científica que veía al hombre ${ }^{2}$ como creatura divina, racional y transformadora, cumbre y fin de la evolución, lo que le daba el derecho de hacer en y con el planeta todo lo que quisiera sin límites. Ante este panorama, los eticistas ambientales comenzaron a formular nuevos patrones de conducta que fueran más éticos y propusieron visiones denominadas biocéntricas y ecocéntricas. Las primeras tomaron como criterio de juicio moral básico el respeto a la vida en sí misma, no solo la humana, bajo el presupuesto de que todo ser vivo posee valor intrínseco, lo que significa que son en sí mismos centros teleológicos de vida (Taylor, 1989: 11). Esta

\footnotetext{
${ }^{2}$ Utilizo el término hombre a propósito, en vez de “ser humano” por ejemplo, porque como se verá más adelante, hay una crítica del ecofeminismo hacia la idea de que toda la especie humana es responsable de los dańos provocados hacia el mundo natural.
} 
nueva visión de la ética se complementó y amplió con la perspectiva ecocéntrica, elaborada originalmente por Aldo Leopold (1949), ${ }^{3}$ y constituida formalmente por Holmes Rolston III (1988) y J. Baird Callicott (1989; 2004). Estos pensadores sostienen que tanto las especies como los ecosistemas son también portadores de valor intrínseco, no sólo los individuos vivientes, como lo propone el biocentrismo; lo que los lleva a sostener la existencia de valores ecosistémicos y con ello ofrecer una visión moral más holista. Esto no niega ni se opone a la idea de que todo individuo posee valor intrínseco; antes bien, reconoce que esta cualidad está presente tanto en los individuos como en los conjuntos bióticos y ecosistemas. En este sentido, para entender esta nueva cosmovisión axiológica integral del mundo natural es muy ilustrativo lo dicho por Leopold (1998): "Una ética de la tierra cambia el papel del Homo sapiens de conquistador de la comunidad de la tierra a simple miembro y ciudadano de ella” (63).

Podemos integrar dentro de las nuevas visiones éticas que comenzaron a gestarse dentro de la ética ambiental a la ecología profunda y el ecofeminismo. La ecología profunda, también conocida como ecofilosofía, se desarrolló en Noruega a finales de la década de 1960 como un movimiento que buscaba promover la preservación natural. Su fundador, Arne Næss (1912-2009), dirigió su crítica a la ecología en tanto disciplina que sólo busca conocer de manera superficial cómo funciona la naturaleza para poder dominarla y manipularla, y con ello extender el dominio antropocéntrico y consumista de la sociedad contemporánea. Næss opone a este tipo de ecología superficial otro tipo de ecología que integre "los enfoques de la naturaleza por parte de los humanos y de la relación de la cultura con la naturaleza en diversos niveles, el de la ontología, el de la ética y el del activismo ambiental" (Arntzen, 2000: 223). Este análisis de la naturaleza sólo puede conseguirse por medio de una ecología profunda que integre los ocho puntos señalados en la plataforma del movimiento ecológico profundo (Næss, 2004: 220-221). "De esta manera, la Ecología profunda va más allá del llamado nivel fáctico y se dirige al nivel de la sabiduría sobre uno mismo y sobre la Tierra" (Devall y Sessions, 2004: 225).

El ecofeminismo, por su parte, señala que "el feminismo ecológico es la tesis de que hay importantes conexiones — históricas, experienciales, simbólicas y teóricas - entre la dominación de las mujeres y la dominación de la naturaleza cuya

${ }^{3}$ El trabajo de Aldo Leopold antecede casi por tres décadas a la conformación de la etica ambiental; no obstante, al momento de clasificar su propuesta, ésta se apega a los criterios del ecocentrismo. Esto no resta en absoluto crédito a que es Leopold el primero en justificar las razones del por qué es necesario ampliar la consideración moral a toda la comunidad biótica y eliminar con esto la visión ética tradicional cargadamente antropocéntrica. 
comprensión es crucial tanto para el feminismo como para la ética ambiental" (Warren, 2004: 233). El término ecofeminismo fue acuñado por Françoise d'Eaubonne (1920-2005) en 1974 en el texto Le féminisme ou la mort en el que "argumentaba que el control masculino de la producción y de la sexualidad femenina conlleva la doble crisis de la destrucción ambiental por la sobreproducción y la sobrepoblación por el exceso de nacimientos" (Mellor, 2000: 63). D’Eaubonne convocó a las mujeres a arrancar a los hombres el poder patriarcal, de manera que se pudiera construir una administración más igualitaria del mundo. Además, enfatizaba el fin de las crisis de la Modernidad, cuya idea central se enfocó en el progreso en tanto que se alcanzó pero a un costo muy alto, pues condujo a una crisis ambiental planetaria. Es por ello que filósofas, como Lizbeth Sagols, consideran que culpar al antropocentrismo sin hacer una distinción de género es incorrecto, pues dicha visión oculta una parte fundamental de la raíz del problema:

En sentido estricto, el antropocentrismo se conformó como un antropo-androcentrismo dualista, violento y excluyente respecto a la mujer y todos los otros vivientes carentes de fuerza y poder, los "débiles". Y a partir del patriarcado, las necesidades de los otros seres vivos carecieron de importancia, ellos no tenían el mismo derecho que los machos poderosos a disfrutar los bienes de la tierra. (Sagols, 2014: 25)

Estas propuestas permearon el discurso de la primera generación de la Ética ambiental; no obstante, fue un discurso desolador, escuchado por pocos, incluso dentro del ámbito filosófico, además de que sus aportaciones fueron poco o nada recibidas en los ámbitos social y político. ${ }^{4}$ Debido a ello, en la década de 1990, surgió una segunda propuesta dentro de la Ética ambiental: el pragmatismo ambiental. Para los filósofos de línea pragmática,

La ética ambiental no estaba respondiendo a los retos y compromisos en el mundo real; se limitaba a hacer sólo un discurso y debate teórico intramuros entre filósofos, el cual, además sólo era entendido por ellos y no estaba sirviendo a la sociedad para orientar posibles soluciones a los problemas ambientales cotidianos. Esto dio origen a que se revisaran, desde la visión del pragmatismo ambiental, las propuestas originales de la ética ambiental, que tenían como intención contribuir en la resolución

\footnotetext{
${ }^{4}$ Me parece importante aclarar que el peso de todas estas propuestas estuvo originalmente cargado hacia su justificación teórica e histórica, debido a ello no tuvieron un impacto social que pudiera concretarse en acciones específicas dentro del ámbito de la política pública. No obstante, algunas de estas corrientes han comenzado a tener una gran influencia social, como es el caso del ecofeminismo que ha ido posicionándose con mucha fuerza en la arena jurídica y política. Ver Mellor (2000) y Puleo (2015).
} 
de los problemas ambientales. Este objetivo, desde la visión de algunos filósofos ambientalistas de línea pragmática (Norton, Katz y Weston) no logró concretarse durante las dos primeras décadas de esta disciplina, lo cual los condujo a elaborar un análisis metateórico de las propuestas hechas por la primera generación de eticistas ambientales y a proponer una metodología pragmática que, a diferencia de las propuestas metaéticas de la primera generación de ética ambiental, parta del análisis de problemas reales específicos y el ofrecimiento de posibles soluciones para resolverlos. Esta propuesta parece ir más en sintonía con la perspectiva social y política, cuya inclinación esencial es dar solución práctica a problemas inmediatos, más que andar buscando fundamentos metafísicos que justifiquen la conducta humana y cómo actuar con base en ellos. (Salazar Ortiz, 2018: 53; las cursivas son mías)

Este giro pragmático en la ética ambiental hizo que comenzara la reflexión sobre problemas ambientales específicos, como la restauración ecológica, la justicia y el derecho ambiental, el uso de organismos genéticamente modificados en los cultivos y su impacto en el entorno natural, la integridad ecológica y recientemente el cambio climático. La indicación base del pragmatismo ambiental es que no basta elaborar una reflexión ético-filosófica sobre estos problemas, sino que debe buscarse y desarrollarse para su resolución un trabajo multidisciplinar colaborativo que integre a expertos en el área de ecología, derecho, sociología, química, entre otros, pero además, a los tomadores de decisiones políticas, pues son ellos los responsables de generar las políticas públicas respectivas para que las ideas vertidas por los expertos puedan concretarse. Parte fundamental en este trabajo es, sin duda, la participación de la sociedad civil, pues son/somos los ciudadanos los que reciben/ recibimos los beneficios o daños de los programas que pudieran aplicarse para resolver los problemas relacionados con el medio ambiente.

La ética ambiental comenzó en el plano terrenal, pero los daños fragmentarios a la naturaleza han dejado de circunscribirse a lo que sucede en la tierra para alcanzar lo que le sucede a la Tierra, y un problema que requiere de toda nuestra atención y actuación es el cambio climático.

\section{Pragmatismo ambiental y cambio climático}

El cambio climático es un hecho que está comprobado por la ciencia. ¿Cuál es el problema para no prestarle atención y realizar acciones inmediatas para contenerlo? El estudio del aumento de la temperatura del planeta comenzó a concebirse en el siglo antepasado por conducto de Svante August Arrhenius (1859-1927), quien 
fue el primer científico en plantear que el incremento en la proporción de dióxido de carbono $\left(\mathrm{CO}_{2}\right)$ generado por la quema de combustibles fósiles, podría acelerar y aumentar el calentamiento de la atmósfera del planeta, y aunque sus cálculos no fueron muy precisos en ese momento, sentó el paradigma para dar inicio al estudio del clima. Guy Stewart Callendar (1898-1964) continuó con el trabajo, y en 1938 publicó un estudio en el que mostraba cómo la actividad industrial entre los años 1890 y 1938 había generado un incremento de 10 \% de dióxido de carbono en la atmósfera, lo que provocó un aumento en la temperatura media del planeta; no obstante, él consideró que éste era positivo, pues retrasaría la llegada de la siguiente glaciación (Callendar, 2008). Arrhenius y Callendar sentaron las bases científicas para el estudio del impacto del $\mathrm{CO}_{2}$, generado por los seres humanos en la atmósfera, pero fueron Charles David Keeling (1928-2005) y Roger Revelle (1909-1991) quienes comenzaron a medirlo formalmente en 1958. Para ello, construyeron una estación de observación en el monte Mauna Loa (Hawai) y otra en la Antártida desde "donde lanzaban globos aeroestáticos todos los días, durante muchos años" (Gore, 2007: 38). De esta manera, "Revelle vio claramente que la expansión económica posterior a la Segunda Guerra Mundial, impulsada por el explosivo crecimiento poblacional y alimentada principalmente por el carbón y el petróleo, probablemente produjesen un peligroso aumento sin precedentes de $\mathrm{CO}_{2}$ en la atmósfera de la Tierra" (Gore, 2007: 38).

Por medio de estos análisis se ha logrado calcular que antes de la era industrial la concentración global del $\mathrm{CO}_{2}$ en la atmósfera era de 280 partes por millón (ppm); cuando comenzó a medirse en 1958, el nivel global de $\mathrm{CO}_{2}$ era de 315 ppm; en 2017 se incrementó a 403 ppm (Planelles, 2017). Estas mediciones demuestran que la tendencia ha mantenido un crecimiento estable; pero el constante aumento en las concentraciones de este gas, sumado a otros como el óxido nitroso $\left(\mathrm{N}_{2} \mathrm{O}\right)$, el metano $\left(\mathrm{CH}_{4}\right)$ y el ozono $\left(\mathrm{O}_{3}\right)$, que en su conjunto se les reconoce como gases de efecto invernadero, son los que han provocado el aumento global de la temperatura de nuestro planeta (Schifter y González-Macías, 2005).

A pesar de la existencia de estos datos, hay personas que dudaron que los cambios en la temperatura de la Tierra fueran reales y producidos por la especie humana, pues los atribuyeron a otros factores como son "movimientos casi imperceptibles en el eje de rotación de la Tierra y el incremento en la actividad volcánica del sol" (Cabrera, 2003: 35). Además de que "durante años, la medición de las temperaturas realizadas por satélites sembró la duda. Los registros establecidos desde la tierra y los efectuados con globos evidenciaban el aumento de la temperatura, pero los datos enviados por los satélites indicaban que, entre 1979 y 1995 la tropósfera se había enfriado" (Cabrera, 2003: 36). 
Con el objetivo de disipar dudas, en 1990 la ONU convocó a más de doscientos climatólogos de todo el mundo para evaluar si las actividades humanas eran realmente las responsables del cambio climático, concluyendo que: "La evidencia no es suficientemente clara para concluir que este calentamiento global es causado por los seres humanos" (Cabrera, 2003: 37). Sin embargo, en 1995 el Panel Intergubernamental de Cambio Climático (IPCC) emitió un segundo informe en el que reconoció que "existen nuevas y más sólidas evidencias de que la mayor parte del calentamiento global observado en los últimos cincuenta ańos es atribuible a actividades humanas" (Cabrera, 2003: 37).

$\mathrm{Al}$ respecto, hay que señalar que si hay diferencias en los datos se debe a que se emplean distintos métodos e instrumentos en sitios diversos, lo cual ocasiona que los resultados que se obtienen sean múltiples y, por lo tanto, diferentes entre un tipo de estudio y otro. En relación con las discrepancias que pueden encontrarse en los datos y las teorías resultantes, debe señalarse que eso es un elemento tradicional y fundamental en el desarrollo de toda disciplina científica, como lo señaló Thomas Kuhn (1971), pues a través de la falsificación y la verificación progresiva de los paradigmas referenciales, se elaboran nuevas predicciones y explicaciones de los hechos. Estas "nuevas teorías" pueden ofrecer una información más acertada, lo que permite generar el avance científico. Este es el caso de las ciencias del clima, en las cuales prevalecen diferencias, pese a las cuales, hay una cosa en la que todos sí están de acuerdo: el clima está cambiando.

A lo anterior se suma que se ha manejado una distinta terminología para nombrar al problema, como lo muestra Gardiner (2004): "La posible confusión sobre el problema del Cambio climático comienza, incluso, con los términos utilizados para describirlo: del 'efecto invernadero' al 'calentamiento global' al más favorecido recientemente 'cambio climático"” (557). Esto puede dejarse de lado, señala Gardiner, ya que lo realmente importante es que sí se está produciendo un cambio antropogénico en el clima y tenemos la obligación moral de frenarlo; entonces "el verdadero desafío climático es ético, y las consideraciones éticas de justicia, derechos, bienestar, virtud, legitimidad política, la relación de la comunidad y la humanidad con la naturaleza están en el centro de las decisiones políticas que deben tomarse" (Gardiner, 2016).

Algunos políticos aprovecharon las diferencias y confusiones de las primeras investigaciones y estudios sobre el cambio climático, así como la falta de un acuerdo general en la información que se obtenía, para concluir que los datos eran "contradictorios" o incluso "falsos", además que en éstos había de por medio "prejuicios" o "intereses creados" que buscaban frenar el progreso y el desarrollo 
económico de las naciones, de hecho le dieron el nombre de climagate..$^{5}$ No obstante, hoy sabemos con certeza que el negacionismo climático es auspiciado por las principales compañías petroleras (ExxonMobil, Chevron, Royal Dutch Shell, British Petroleum), y grupos políticos conservadores de Estados Unidos. Estos negacionistas se agrupan en torno al Instituto Heartland que es un laboratorio de ideas con sede en Chicago dedicado a promover soluciones de libre mercado. Este Instituto organiza anualmente, desde 2008, su propia Conferencia Internacional sobre cambio climático, cuyas siglas en inglés, ICCC, solo se desvían por una letra de la autoridad mundial en materia de cambio climático, el IPCC de las Naciones unidas, que es una iniciativa colaborativa de miles de científicos y 195 Gobiernos nacionales. Por el contrario, la mayoría de los integrantes y ponentes en las conferencias organizadas por el Instituto Heartland "ni siquiera son científicos, sino 'aficionados' al tema: ingenieros, economistas y abogados" (Klein, 2020: 52). Algunos miembros de este instituto reconocen no estar en desacuerdo con los datos ofrecidos por el IPCC, pero lo que les alarma es la repercusión económica de éstos en la política y por ende en los negocios de la industria del petróleo. Frente a esto, "los negacionistas están haciendo algo más que proteger sus cosmovisiones personales: están protegiendo poderosos intereses políticos y económicos que se han beneficiado increíblemente del modo en que Heartland y otros foros parecidos han enturbiado el debate sobre el clima" (Klein, 2020: 65). No está de más señalar que "los negadores del cambio climático no solo son conservadores, sino que, en su inmensa mayoría, son también blancos y varones, y ese es un grupo social con ingresos superiores a la media" (Klein, 2020: 67). Este es un dato significativo de la crítica del ecofeminismo, pues se trata de "un cierto de tipo de hombres", y no la especie humana, los que se han encargado de dominar y explotar el mundo sin restricciones y sin ningún tipo de remordimiento moral: "El problema de verdad es que esa visión del mundo suya (basada en la dominación, como digo) les proporciona las herramientas intelectuales necesarias para dar ya por perdidas a secciones enteras de la población humana e, incluso, para racionalizar la posibilidad de lucrar con semejante debacle" (Klein, 2020: 69).

${ }^{5}$ Los negacionistas climáticos acusaron a algunos climatólogos pertenecientes al IPCC de haber manipulado su información y datos con la intención de mostrar un aumento en la temperatura del planeta, sin que esto fuera cierto o lo hubieran comprobado. Posteriormente se descubrió que los negacionistas ingresaron a las cuentas de correos y habían hackeado y distorsionado el intercambiaban de información entre los científicos del clima. A pesar de que esto se aclaró públicamente, los negacionsitas consiguieron generar un gran escepticismo en el trabajo del IPCC. 
Los negacionistas tampoco están considerando los resultados de la contaminación, el deterioro ambiental y los daños a la salud humana, producto de la explotación intensiva de los yacimientos petroleros y el uso generalizado de los combustibles fósiles.

En este rubro destacan importantes impactos en la salud a consecuencia de la emisión de contaminantes a la atmósfera, hidrósfera y al suelo. Los principales contaminantes son el bióxido de carbono, el metano, los óxidos de nitrógeno, o los derrames de hidrocarburos en mares y regiones continentales a causa del transporte y manejo inadecuado del petróleo crudo o de sus productos derivados. También es notorio el impacto directo al ambiente y a los ecosistemas por causa de los métodos de explotación y refinación llevados a cabo. Además de la emisión de bióxido de carbono se han incrementado las emisiones de compuestos clorofluorocarbonados, los cuales han favorecido el efecto invernadero $y$, en consecuencia, el surgimiento de un fenómeno nuevo identificado como el cambio climático. (Ortuño; 2009: 20-21)

Por otra parte, para la colocación de instalaciones petroleras se han expulsado a grupos humanos de sus territorios ancestrales, y en esos sitios se han generado problemas de salud en las comunidades humanas (cáncer, esterilidad, deformaciones congénitas en recién nacidos) y de animales cercanos a los pozos, oleoductos y gasoductos. Para conseguir sus fines extorsionan a los gobiernos haciéndolos cómplices de sus delitos ambientales y asesinan a quienes critican y se oponen a sus intereses comerciales (Werner y Weiss, 2003: 64-81). La periodista Naomi Klein (2020) ha hecho un relato muy detallado de todos estos asuntos, y en una parte de su trabajo señala que:

En un mundo donde impera la cordura, esta concentración de desastres, sumada a la crisis climática general, habría propiciado ya cambios políticos significativos. Se habrían decretado topes y moratorias, y se habría iniciado un abandono gradual de estas formas extremas de obtención de energía. Que nada de eso haya ocurrido, y que sigan concediéndoles licencias y arrendamientos para la realización de actividades extractivas cada vez más peligrosas, puede atribuirse en parte a la presencia de una inveterada corrupción, tanto legal como ilegal. (410)

Con lo dicho, puede verse que son las empresas extractoras y comercializadoras de los hidrocarburos las principales creadoras y promotoras del cambio climático, de la contaminación de suelos y mares en los sitios donde colocan sus instalaciones, 
además de muchas injusticias sociales que los acompañan. Aun así, todos tenemos que contribuir para frenar el constante incremento de quema de combustibles fósiles y con ello del aumento de la temperatura global del planeta. Pero la realidad es que somos muy dependientes de éstos debido a que han movido el mundo desde los inicios del siglo xx: "La generación y procuración de energía en el mundo actual tienen como vectores principales a los energéticos fósiles, principalmente petróleo, gas natural y carbón. Estos tres vectores energéticos representan más del $90 \%$ de participación como fuentes de energía" (Ortuño, 2009: 17). Hoy en día dependemos de ellos, así que todos contribuimos directamente en la contaminación y en el cambio climático. Por poner un ejemplo, por cada "litro de gasolina que se quema se producen 2.43 kilogramos de bióxido de carbono" (Schifter y González-Macías, 2005: 130). Esto provoca que el aire en las ciudades esté cada vez más contaminado, lo que genera en la población dańos a la salud, particularmente enfermedades cardiovasculares y respiratorias. Al respecto, la Organización Mundial de la Salud (OMS) publicó en su centro de prensa, en marzo de 2014, que "cada ańo mueren 7 millones de personas debido a la contaminación atmosférica” (OMS, 2014). La Organización Panamericana de la Salud (OPS) señala que "en todo el mundo, 4.2 millones de muertes prematuras fueron atribuibles a la contaminación del aire ambiental exterior en el 2016. Alrededor del $88 \%$ de estas muertes ocurren en países de ingresos bajos y medios" (OPS, 2018). Estudios más recientes muestran que esta cifra sigue al alza, pues investigadores alemanes publicaron un informe en el que señalan que "la cifra de muertes provocadas por la polución del aire se eleva a 8.8 millones de personas, en comparación con los 4.5 millones calculados por la Organización Mundial de la Salud" (Lelieveld et al., 2019). En ese trabajo también se alerta que la contaminación del aire sobre la salud humana está subestimada y se invita a los gobiernos y agencias públicas a establecer políticas eficaces para reemplazar los combustibles fósiles por energías renovables limpias.

El mal uso y despilfarro de estas energías no se considera o se juzga como una conducta inmoral porque no se percibe en ella un daño directo e inmediato a alguien, lo que sería la base para juzgar una acción como moral o inmoral. Esto se debe a que muy pocas personas saben cómo se extrae y refina el petróleo, que dichos procesos son altamente contaminantes, que dañan a los ecosistemas, a los animales pertenecientes a ellos y a comunidades humanas cercanas a las instalaciones. Lo que sí es un hecho es que, a pesar de ese desconocimiento, hay cada vez una mayor conciencia social y política de que la producción irresponsable y el uso indiscriminado de la energía producida con combustibles fósiles están provocando el cambio climático, y que debe ponérsele un freno junto con algunas 
soluciones como migrar a la generación de energías limpias, que pueden ser eólicas, solares, marítimas o geotérmicas.

El cambio climático tiene como principal fuente de origen el uso de combustibles fósiles, pero no es el único, hay que agregar los métodos de explotación agropecuaria y agrícola debido a que:

La cuarta parte de las emisiones de metano causadas por la actividad humana provienen de los desechos de los animales que consumimos y de sus excrementos. Se estima que la emisión anual de metano proveniente de los animales es del orden de los 100 millones de toneladas, y la cuarta parte se genera por la descomposición posterior de los desechos animales. Los animales producen metano por la llamada fermentación entérica, proceso por el cual la materia, los azúcares y los ácidos orgánicos son convertidos por las bacterias y otros microbios en el tracto digestivo del animal [...] Los animales rumiantes, como las vacas, emiten más metano que los no rumiantes, como los caballos y los cerdos. Por ejemplo, las vacas generan alrededor de $35 \mathrm{~kg}$ de metano por cabeza anualmente; y si están confinadas físicamente producen el doble. (Schifter y González-Macías, 2005: 73-74)

Estas actividades de crianza animal para consumo humano también han provocado que se generen daños en los ecosistemas, producto de la deforestación de bosques y selvas para el monocultivo de granos transgénicos con que se alimentan. Además la contaminación de ríos lagos y mares en los que se vierten sus orines, excrementos y los desechos de los animales muertos (sangre, huesos, pieles): "Si en el sector de los alimentos para consumo humano se aumentara la producción de vegetales y se disminuyera la producción de carne en la medida de lo posible, se podría mejorar la eficiencia de la energía y reducir las emisiones (especialmente de N2O y CH4) del sector agrícola” (Schifter y González-Macías, 2005: 121). Debido a todo esto, la ONU, por conducto del IPCC, en agosto del 2019 hizo un llamado a reducir el consumo de carne y a contribuir con ello en la disminución del cambio climático (Redacción BBC News Mundo, 2019).

Sin duda es preocupante lo que le está sucediendo y puede llegar a suceder a nuestros congéneres con el cambio climático, pero la ética ambiental nos ha mostrado que esta preocupación debe tener un mayor alcance moral e incluir a otras especies con las que compartimos este mundo, así como los bienes naturales que hacen posible el sostenimiento de la vida. Ante este escenario, y buscando ser congruentes con una ética ambiental ecocéntrica que integre a todos los seres con los que compartimos este planeta, debemos considerarlos no sólo como un medio para nuestros objetivos, sino como fines en sí mismos. Por ejemplo, dejar de con- 
sumir productos de origen animal con la intención de hacer disminuir la generación de gases de efecto invernadero, pero sólo como un beneficio exclusivamente de nuestra especie, no logra una consideración moral integral; ésta debe hacerse pensando que con esto puede disminuirse, o incluso abolirse, la explotación y el maltrato de millones de animales, ya que su crianza para la producción de alimentos conlleva dolor y sufrimiento derivado del hacinamiento, mutilación y alimentación artificial al que se les somete. ${ }^{6}$ Además, si se disminuye o elimina el consumo de productos de origen animal, se contribuye a salvaguardar los ecosistemas cercanos a las granjas y ganaderías de la contaminación que en éstas se genera, también frenar la deforestación y la expansión de los monocultivos transgénicos, especialmente en Sudamérica, para alimentarlos. De esta manera podemos ver que:

El cambio climático no solo es malo desde un punto de vista moral en cuanto dificulta y pone en aprietos la dignidad, calidad de vida e, incluso, la supervivencia futura de los seres humanos, sino también en tanto en cuanto dificultara y pusiera en aprietos la calidad de vida, el bienestar (intereses, bien en sí mismo, etc.) e, incluso, la supervivencia de otros seres naturales que conviven con nosotros en nuestro planeta. (Velayos, 2008: 195)

A esto hay que agregar que cuando se señala que el cambio climático está provocando la extinción de numerosas especies vegetales y animales, éstas deben preocuparnos, no por el perjuicio o beneficio que esto pueda provocar a nuestra especie, sino por el dańo que reciben producido por nosotros, tanto en ambientes controlados como en espacios salvajes, derivado de la contaminación o devastación de sus hábitats provocado por el cambio climático, el cual está alterando el estado del tiempo y el clima en varias regiones del mundo, perturbando con ello los procesos naturales de procreación, crianza y alimentación de algunas especies (WWF, 2015).

Debido a esta dependencia energética y los modos habituales de alimentación actual, resulta muy complicado para la sociedad abandonarlos, pero es aquí donde entra la ética, en cuanto dispositivo de análisis de los patrones humanos de conducta, porque puede integrar en su estudio una reflexión sobre lo correcto o incorrecto de nuestras acciones en relación con el cambio climático, y en este sentido denunciar que estamos amenazando la continuidad de la vida en nuestro planeta, valor fundamental de nuestra existencia y del de millones de especies. La ética puede provocar un cambio en la actitud individual y social para generar una sinergia moral ambiental que motive a las personas a modificar sus estilos de vida, ya que

${ }^{6}$ Ver Singer (1999) y Singer y Mason (2009). 
con éstos se está llevando a Gaia, nuestra madre Tierra, a la muerte, por lo que se requiere un cambio de percepción y de conducta urgentes, como lo ha hecho notar Lovelock (2007):

El concepto de Gaia, un planeta vivo, es para mí la base de cualquier ecologismo coherente y práctico. Contradice la extendida creencia de que la tierra es una propiedad, una finca, que existe sólo para ser explotada por la humanidad. Esa falsa convicción de que somos propietarios del planeta, o tan siquiera sus administradores, nos permite seguir hablando de políticas ecologistas con la boca pequeña mientras continuamos nuestras actividades como si nada [...] Pocos, incluso entre los ecologistas y los climatólogos, parecen comprender la potencial gravedad de la inminente catástrofe global que se avecina. Y, entre los que lo hacen, la comprensión está solo en la mente consciente, no genera la reacción visceral de miedo que sería de esperar. Nos falta una intuición, un instinto, que nos diga cuándo Gaia está en peligro. (198)

En la década de 1970, Hans Jonas (2004) ya hacía referencia al miedo que deberíamos comenzar a sentir producto del desarrollo tecnológico, cuyo resultado está conduciendo a la humanidad a poner en riesgo su existencia y la del planeta. Jonas lo nombró "heurística del temor". En palabras de este autor, signfica que "solamente sabemos qué está en juego cuando sabemos que está en juego" (Jonas, 2004: 16). Lo que está en juego es la supervivencia física del hombre y con ella "la integridad de su esencia, la ética" (Jonas, 2004: 16). El riesgo de perderlo todo debería obligar a las personas a superar el subjetivismo axiológico y pensar en el actual modo de ser del hombre y en su deber, que no es otro que ampliar su responsabilidad hacia el mundo y el futuro de éste, en otras palabras, una ontoética interespecie e intergeneracional:

La ética se concentraba en la cualidad moral del acto momentáneo mismo, en el que había de tenerse en cuenta el derecho del prójimo que con nosotros convivía. Mas, bajo el signo de la tecnología, la ética tiene que ver con acciones — si bien ya no las del sujeto individual — de un alcance causal que carece de precedentes y que afecta al futuro [...] Todo ello coloca la responsabilidad en el centro de la ética dentro de unos horizontes espacio-temporales proporcionados a los actos. (Jonas, 2004: 16)

La ética, para Jonas, ha dejado de ser el sitio exclusivo de reflexión de lo humano y la responsabilidad de un beneficio alcanzable sólo para el hombre cercano espacio-temporal; por lo que, ética y responsabilidad deben extenderse más allá de 
lo propiamente humano e incluir el mundo y el futuro, dentro de éste la futura generación de seres que lo habitarán. ¿Cómo llevar a la práctica estas ideas?

En la primera parte de este trabajo señalé que la ética ambiental propuso un cambio de paradigma moral, es decir, dejar de pensar en ella de modo antropocentrista y hacerlo de manera ecocentrista, lo que derivó en un antiantropocentrismo. Esto desató una gran discusión debido a que, en tanto que somos seres humanos, no podemos ver y valorar el mundo desde otra óptica que no sea la humana, es decir, no podemos verlo y entenderlo como un gorila, un oso, un pez y menos como un árbol o un bosque; así que el pragmatismo ambiental reelaboró esta visión de la ética ambiental, por conducto del filósofo Bryan Norton (1984), proponiendo un antropocentrismo débil en oposición a un antropocentrismo fuerte. Éste se caracteriza porque sus decisiones y acciones se basan en preferencias sentidas ( felt preference), es decir, son deseos o gustos que se espera satisfacer sin que en ellos medie una reflexión moral previa, lo que conlleva a imponer su deseo por encima del Bien. El antropocentrismo débil, por el contrario, se caracteriza por tener una visión más amplia del mundo, orientada por otros tipos de consideraciones a las cuales Norton nombra preferencias ponderadas (considered preference). Éstas son posturas que adopta una persona antes de actuar y aluden a "los deseos o necesidades que podrían ser expresados tras una cuidadosa deliberación, incluidos los juicios donde los deseos o necesidades son coherentes con una determinada visión del mundo; visión que, en cuanto tal, incluye teorías científicas y un marco metafísico que las interprete como expresión de ideales estéticos y morales" (Norton, 1984: 68).

Norton señala que las preferencias sentidas pueden ser racionales, pero no necesariamente éticas. Por ejemplo, las personas pueden justificar que llevan una dieta en la que integran un alto porcentaje de alimentos de origen animal por cuestiones de salud, ya que el cuerpo humano requiere proteínas y vitaminas que sólo se encuentran en la carne, la leche y el huevo. Además, pueden decir que los seres humanos siempre se han nutrido y complacido su paladar con estos productos, ya que nunca se ha considerado inmoral; por el contrario, es algo natural y completamente normal. Esta decisión la asume mucha gente sin informarse del trato que reciben los animales en la granjas y establos, del impacto ambiental de su crianza y sostenimiento, y de los daños a la salud humana, a pesar de que existe actualmente mucha información al respecto.?

Este es un ejemplo de cómo funciona un antropocentrismo fuerte que opera bajo el criterio de satisfacer preferencias sentidas. Una consideración ponderada,

\footnotetext{
${ }^{7}$ Ver Rifkin (1992) y Robbins (2001).
} 
en este caso, sigue el camino contrario, ya que antes de comprar productos de origen animal se pregunta acerca del trato que recibieron éstos, del impacto ambiental de su manutención y de los beneficios o perjuicios que trae para la salud humana alimentarse con ellos; entonces, una vez que cuenta con estos datos (muchos de ellos con evidencia científica) puede tomar una decisión ponderada bajo un criterio deliberativo ético-práctico que puede derivar en dejar de consumirlos, disminuir su consumo o comprarlos en establecimientos comprometidos con una crianza humanitaria y orgánica. ${ }^{8}$

Este mismo criterio se puede aplicar para el consumismo, ya que con éste se solapa la devastación de la naturaleza a cambio de un bienestar humano ficticio, el cual es promovido por empresas y marcas comerciales a través de sus redes de publicidad que incitan al consumo de un cúmulo de productos (ropa, calzado, dispositivos electrónicos, autos, casas, viajes, alimentos exóticos, etcétera), muchos de ellos realmente innecesarios. La mayoría de la gente, hay que decirlo una vez más, no es consciente de que, para que todas esas cosas lleguen al mercado, pasan por un proceso denominado economía de materiales que integra la extracción, producción, selección, distribución, comercialización y desecho (Leonard, 2013). La mayoría de los consumidores sólo ven una etapa de este proceso, la comercialización; todo lo que ocurre en las otras fases se desconoce, y por eso no se dan cuenta del daño ambiental y/o el perjuicio moral que una compra puede conllevar. Las etapas uno a tres implican explotación y contaminación de recursos naturales, así como explotación laboral, y la última, injusticias ambientales, ya que muchos de los materiales que se descartan —en términos coloquiales, que se desechan a la basura - se depositan en las tierras y/o mares habitados por gente pobre, provocando injusticias ambientales.

Poner en práctica un antropocentrismo débil, frente a este panorama, consiste, antes que todo, en una mayor conciencia moral de nuestras decisiones, en aprender a ponderar y deliberar entre aquello que realmente sí se necesita, de aquello que solamente se desea; en darse cuenta de que seguir por el rumbo de la explotación irracional de bienes naturales, su destrucción y contaminación, está dejando al mundo natural sin resiliencia, es decir, sin capacidad de producir, de reproducirse y de autorrepararse cuando es dańado. Esto debería despertar en nosotros un sentimiento de temor/miedo y obligarnos a actuar con una ética más amplia e inclu-

\footnotetext{
${ }^{8}$ Respecto a este tema hay dos posturas: el liberacionismo y el abolicionismo. La primera sigue el criterio de que si los animales reciben un trato humanitario no habría razones éticas para no consumirlos. Éste es seguido por los ovolactovegetarianos. La segunda, por el contrario, rechaza todo uso que se haga de los animales y es practicada por los veganos (Horta, 2017; Regan, 2004).
} 
yente que nos haga más conscientes de la responsabilidad que tenemos con la totalidad del mundo que nos rodea y del compromiso de preservarlo, por nuestro propio bien y el de las generaciones futuras.

Para concluir este apartado, quiero señalar que la solución para enfrentar el cambio climático, y todos los daños que de éste se derivan, desde el enfoque del pragmatismo ambiental, sólo puede abordarse por medio de políticas públicas claras en todos los ámbitos: municipal, estatal, federal e internacional. Éstas deben estar justificadas y avaladas con elementos jurídicos que permitan regular el manejo transparente de la información científica y de la implementación tecnológica necesaria para resolver problemas locales, nacionales e internacionales. Y lo principal, basarse en principios éticos y normas morales previamente ponderadas que ofrezcan certeza a la ciudadanía al momento de deliberar sobre las propuestas de solución que pretendan realizarse y que parezca que serán las más convenientes.

\section{Pragmatismo ambiental y política pública relacionada con el cambio climático}

El cambio climático ha sido uno de los temas políticos más tratados durante el último cuarto del siglo pasado y lo que va de éste. Los compromisos nacionales por país firmante para frenar el aumento de la temperatura media del planeta se remontan a 1992 con la Convención marco de las Naciones Unidas sobre el Cambio Climático, y en 1998 con el Protocolo de Kioto. A partir de allí, en las subsiguientes Conferencias de las partes de las Naciones Unidas sobre Cambio Climático (COPs) se han derivado convenios, acuerdos, directrices, objetivos, guías de acción, como la Carta de la Tierra, la Agenda 2030, los Objetivos del Desarrollo Sostenible (ODS). Podríamos decir que las buenas intenciones y los deseos por evitar sobrepasar el umbral de $1.5^{\circ} \mathrm{C}$ de la temperatura media del planeta sobran en el papel, lo que falta son acciones prácticas concretas.

En la COP21, que se celebró en París en el 2015, se señaló que los países tenían que ser mucho más ambiciosos por el bien del planeta, es decir, que todos tenían que tener compromisos muy claros de cómo iban a atender el tema del cambio climático por medio de acciones prácticas concretas como son: reducir la deforestación de los bosques, la pérdida de la biodiversidad, disminuir el uso de combustibles fósiles, hacer un uso más eficiente de la energía a través del desarrollo de la ecotecnología basada en las energías renovables sustentables, etcétera. Sin embargo, un estudio realizado en 2018 muestra que las metas que los países se propusieron no están siendo atendidas: 
Establecer objetivos sólidos en las leyes y políticas nacionales es crucial para la credibilidad de los compromisos de los países con el Acuerdo de París, como se establece en sus Contribuciones Determinadas Nacionalmente (CDN). Sin embargo, mientras 157 de 197 Partes en el Acuerdo han establecido objetivos de reducción de emisiones para toda la economía en sus CDN, solo 58 lo han hecho dentro de las leyes o políticas nacionales; solo 17 de ellos son consistentes con los establecidos en las CDN. Por lo demás, no hay datos suficientes para la comparación. Estas inconsistencias crean dudas sobre la probabilidad de alcanzar los objetivos del Acuerdo. (Nachmany y Mangan, 2018: 1)

Al respecto, Mann y Wainwright (2018) señalan algunas inconsistencias claves de la COP21, entre ellas, que "el acuerdo de París no separa a los Estados partes en grupos con compromisos diferentes a partir de su riqueza o ingreso, a diferencia del Protocolo de Kioto de 1997” (76), además que:

El lenguaje del cuarto artículo del Acuerdo de París indica un compromiso entre los principales Estados capitalistas (liderados por Estados Unidos y la Unión Europea) y los países en vías de desarrollo (representados efectivamente por China e India). Cada país promete recortes — "que las emisiones mundiales de gases de efecto invernadero alcancen sus puntos máximos lo antes posible"-, pero los niveles y las fechas límites no se definen. (77)

En la COP26, prevista para realizarse en el 2019, lo que se iba a hacer era revisar cómo iban avanzando estos objetivos por país. Desafortunadamente, por motivos de la pandemia de la COVID-19, no se pudo llevar a cabo, pero en general las proyecciones no eran positivas. Esto significa que es posible que se alcance en el futuro cercano un aumento de $2{ }^{\circ} \mathrm{C}$ por encima de la temperatura media del planeta, lo que pondría en riesgo nuestra forma de vida actual. Si eso ocurre, vamos a comenzar a perder muchos ecosistemas, biodiversidad y cultivos, y seguridad alimentaria, acompañadas de migraciones climáticas, pobreza extrema y que mucha gente perezca.

Por supuesto, este no es un escenario agradable; la pregunta es ¡cómo hallar una solución? Rosenberg (2019) señala que lo primero que debe hacerse para mitigar el cambio climático es comprender que en él están entrelazadas la política, la filosofía y la economía por un término técnico de economía: "el bien público". Este "bien" no es una mercancía, es decir, algo que se pueda comprar, pero sí es un "producto" con dos importantes propiedades que están ausentes en otros: la primera, está identificada con algo que se consume sin que se compita por ese bien, 
por ejemplo, la luz emitida por el alumbrado público es algo que está ahí para todos y no se agota su luz por más que pasen por ella. La segunda, se trata de un bien que no es excluyente, así que todos pueden hacer uso de éste; continuando con el ejemplo, cualquier persona puede usar esa luz mientras esté encendida. Si esto se traslada al compromiso adoptado en la Conferencia de París, de evitar que las temperaturas globales aumenten más de $1.5^{\circ} \mathrm{C}$, ese resultado sería un bien público, es decir "beneficiaría e incluiría a todos sin que pudiera agotarse"; pero para ello debe existir el acuerdo, pues "no se puede consumir nada de ese bien a menos que esté ahí, y no importa cuánto se consuma en beneficio personal, eso no reducirá la cantidad que se puede consumir" (Rosenberg, 2019: s. p.). Al igual que con el alumbrado público, unos podrían beneficiarse más que otros, pero sin un acuerdo y el compromiso de cumplirlo, nadie se beneficia.

Este problema se conoce en filosofía como "el dilema del prisionero", el cual, aplicado al Acuerdo de París, sería algo así como: si todos los países se comprometen a bajar sus emisiones de $\mathrm{CO}_{2}$, todos se benefician por igual; pero, si todos lo hacen menos Estados Unidos, éste se beneficia, a pesar de todos. De forma contraria, si Estados Unidos se compromete, pero China y la India no, no tiene sentido que los Estados Unidos lo haga, es decir, no puede crearse un bien público, en este caso, un bien universal, sin establecerse previamente un acuerdo por medio del que se pueda conseguirse.

Este tipo de anarquía, señala Rosenberg, fue puesta al descubierto en el siglo xviI por Thomas Hobbes, quien reconoció que el estado de derecho, "se consume sin rivalizar y sin excluir, incluso a los más débiles, los más pobres" (Rosenberg, 2019: s. p.). Bajo este criterio, las Leyes pueden beneficiar a todos, aún así, a unos más que a otros, pero siempre es mejor contar con éstas, pues conferirán algún tipo de beneficio. Pero para que esto sea posible, "Hobbes argumentó que la única forma de proporcionar este bien público es que cada uno de nosotros entregue todo el poder al estado para que éste pueda obligar a obedecer la ley" (Rosenberg, 2019: s. p.). Esto resolvería la anarquía. Rosenberg señala que no se le prestó suficiente atención a Hobbes para resolver el dilema del prisionero; en su lugar, se buscaron otras salidas con las que, de manera voluntaria, se vieran la ley y su cumplimiento como un beneficio público, pero esto no logró conseguirse, pues el bien propio se antepone, en muchos casos, por encima del bien público. Rosenberg señala que Elinor Ostrom (2011) fue quien proporcionó una receta sobre cómo evitar el dilema del prisionero y con ello conseguir hacer un uso justo de los bienes comunes. Ella identificó que las condiciones bajo las cuales los grupos logran resolver dicho dilema es creando voluntariamente instituciones (reglas, normas, prácticas) de las que se beneficia cada miembro, sin competir ni excluir a nadie: 
Los ingredientes necesarios son claros: los participantes deben acordar quién está en el grupo; hay un conjunto único de reglas que todos los participantes deben obedecer; el cumplimiento se controla de manera efectiva, con castigos graduados por su violación; la ejecución y la adjudicación son asequibles; y las autoridades externas tienen que permitir que los participantes obedezcan las reglas. Finalmente, a largo plazo, el grupo que proporciona el bien público a sus miembros debe estar anidado y autorizado por grupos de nivel superior. Estos, a su vez, persisten cuando pueden proporcionarse a sí mismos un conjunto diferente de reglas, normas, leyes e instituciones no excluibles, consumidas sin competir por ellas y que sean mutuamente beneficiosas. (Rosenberg, 2019: s. p.)

No es difícil darse cuenta, indica Rosenberg, que es casi imposible que los 200 países participantes en las COPs acepten la receta de Ostrom, pues ninguno está dispuesto a entregar su soberanía, pero al menos esto ayuda a que la sociedad reconozca a qué se enfrenta. Es por ello por lo que los ciudadanos deben comenzar a agruparse por su cuenta para buscar soluciones y exigir a sus gobernantes generar respuestas locales en sus comunidades (de alcance municipal y estatal), y abonar así a una solución frente al problema del cambio climático (a nivel nacional e internacional); de esta manera puede conseguirse que muchas personas se beneficien de ese bien público.

Los gobiernos y corporaciones también deben realizar cambios en sus maneras de atender el problema del cambio climático, incorporando estrategias y desarrollos tecnológicos que contribuyan a disminuir el problema, como el empleo de fuentes alternativas de generación de energía y combustibles menos contaminantes, protección de áreas naturales (selvas, bosques, manglares, arrecifes, etcétera) y especies en peligro de extinción, lo que abonaría a la creación de un bien público del que todos podríamos beneficiarnos. ¿Puede suceder? Rosenberg llega a la siguiente conclusión:

Los filósofos han pasado mucho tiempo estudiando ciencias. Han llegado a la conclusión de que no existe una lógica del descubrimiento científico, ni una receta para el próximo avance y, por lo tanto, ningún algoritmo para mejorar nuestra tecnología. El descubrimiento científico es casualidad. Todo lo que podemos hacer es mejorar las posibilidades de la ciencia de sacarnos de este lío: educar a los científicos, apoyar la investigación pura, difundirla libremente y recompensarla con la inmortalidad, no solo con el dinero. (Rosenberg, 2019: s. p.) 
En otras palabras, no hay una receta mágica que pueda emplearse para solucionar el problema del cambio climático. Lo que urge es cambiar los paradigmas de la ciencia y la tecnología que han incitado al ser humano a pasar por encima de otras especies y la propia, cegados exclusivamente por el poder y la avaricia. Es por ello por lo que se requieren nuevos modelos sociales y educativos que inculquen en todos los niveles la búsqueda del bien público, que estén orientados por los criterios propuestos por el pragmatismo ambiental de actuar poniendo en práctica una ponderación y deliberación responsable, guiarse "por preferencias consideradas y no solo sentidas, es decir, deben predominar las preferencias deliberativas que toman en cuenta los efectos a largo plazo" (Sagols, 2011: 55). Este es un camino deseable si queremos seguir viviendo en un mundo menos caliente.

\section{Referencias bibliográficas}

Arntzen, Sven. (2000). “¿Haciéndole un bien a la naturaleza? Ecofilosofía y la ética de la restauración ecológica” (Alejandro Tomasini Bassols, Trad.). En Teresa Kwiatkowska y Ricardo López Vilchis (comps.), Ingeniería genética y ambiental. Problemas filosóficos y sociales de la biotecnología. México: Plaza y Valdés. 221-233.

Cabrera, Adriana. (2003). Calentamiento global. Las dos caras del efecto invernadero. Buenos Aires: Longseller.

Callicott, J. Baird. (1989). In defense of the land ethics. Estados Unidos: State University of New York Press.

Callicott, J. Baird. (2004). “Teoría del valor no antropocéntrica y ética ambiental” (Héctor Islas Azaïs, Trad.). En Margatita Valdés (comp.), Naturaleza y valor. Una aproximación a la ética ambiental. México: FCE; UNAM-IIF. 99-117.

Devall, Bill; Sessions, George. (2004). "Ecología profunda" (Alicia Herrera Ibáñez, Trad.). En Margarita Valdés (comp.), Naturaleza y valor. Una aproximación a la ética ambiental. México: FCE; UNAM-IIF. 225-231.

Gardiner, Stephen M. (2004). "Ethics and global climate change". Ethics, 114(3), 555-600. https://doi.org/10.1086/382247.

Gardiner, Stephen M. (2016). "Why climate change is an ethical problem" (en línea). The Washington Post; Opinions. Recuperado el 16 de junio 2020 de https:// www.washingtonpost.com/news/in-theory/wp/2016/01/09/why-climatechange-is-an-ethical-problem/.

Horta, Oscar. (2017). Un paso adelante en defensa de los animales. España: Plaza y Valdés. 
Jonas, Hans. (2004). El principio de responsabilidad. Ensayo de una ética para la civilización tecnológica (Javier Ma. Fernández Retenaga, Trad.). Barcelona: Herder.

KleIN, Naomi. (2020). Esto lo cambia todo. El capitalismo contra el clima (Albino Santos Mosquera, Trad.). Barcelona: Paidós.

Kunn, Thomas. (1971). La estructura de las revoluciones cientificas (Carlos Solís Santos, Trad.). México: FCE.

Lelieveld, Jos; et al. (2019). "Cardiovascular disease burden from ambient air pollution in Europe reassessed using novel hazard ratio functions". European Heart Journal, 40(20), 1590-1596. https://doi.org/10.1093/eurheartj/ehz135.

Leonard, Annie. (2013). La historia de las cosas (Lilia Mosconi, Trad.). Argentina: FCE.

Leopold, Aldo. (1998). "La ética de la tierra" (Alicia Herrera Ibáńez, Trad.). En Teresa Kwiatkoswska y Jorge Issa (comps.), Los caminos de la ética ambiental. Una antología de textos contemporáneos. México: CONACYT; UAM-I; Plaza y Valdés. 61-77.

Lovelock, James. (2007). La venganza de la Tierra. La teoría de Gaia y el futuro de la humanidad (Mar García Puig, Trad.). México: Planeta.

Mann, Geoff; WaInwright, Joel. (2018). Leviatán climático. Una teoría sobre nuestro futuro planetario (Victor Altamirano. Trad.). Madrid: Biblioteca Nueva.

Mellor, Mary. (2000). Feminismo y ecología. México: Siglo XXI.

Nachmany; Michal; Mangan, Emily. (2018). Aligning national and international climate targets. Londres: Grantham Research Institute on Climate Change and the Environment; The London School of Economics and Political Science. Recuperado el 21 de junio de 2020 de https://www.lse.ac.uk/granthaminstitute/publication/targets/.

Norton, Bryan. (1984). "Environmental Ethics and Weak Anthropocentrism”. Environmental Ethics, 6(2), 131-148. https://doi.org/10.5840/enviroethics 19846233.

Organización Mundial de la Salud (OMS). (2014). "7 millones de muertes cada año debidas a la contaminación atmosférica” (en línea). Centro de prensa. Recuperado el 26 de abril de 2020 de https://www.who.int/mediacentre/news/ releases/2014/air-pollution/es/.

Organización Panamericana de la Salud (OPS). (2018). “Contaminación del aire exterior y en la vivienda: preguntas frecuentes" (en línea). Recuperado el 26 de abril de 2020 de https:/www.paho.org/es/temas/calidad-aire-salud/ contaminacion-aire-ambiental-exterior-vivienda-preguntas-frecuentes. 
Ortuño, Salvador. (2009). El mundo del petróleo. México: FCE.

Ostrom, Elinor. (2011). El gobierno de los bienes comunes. La evolución de las instituciones de acción colectiva. México: FCE; UNAM-IIS.

Puleo, Alicia H. (ed.). (2015). Ecología y género en diálogo interdisciplinar. Madrid: Plaza y Valdés.

Redacción BBC News Mundo. (2019). "Cambio climático: por qué el consumo de carne y lácteos tiene tanto impacto” (en línea). BBC News; Mundo. Recuperado el 5 de junio de 2020 de https://www.bbc.com/mundo/noticias-49279749.

Regan, Tom. (2004). The case for animal rights. Estados Unidos: University of California Press.

Rifkin, Jeremy. (1992). Beyond beef. The rise and fall of the cattle culture. Estados Unidos: Penguin Group.

Robbins, John. (2001). The food revolution. How your diet can help save your life and our world. Estados Unidos: Conari Press.

Rolston, Holmes, III. (1988). Environmental ethics: duties and values in the natural world. Estados Unidos: Temple University Press.

Rosenberg, Alex. (2019). "What kind of problem is climate change?" (en línea). The New York Times; Opinion. Recuperado el 25 de abril de 2020 de https:// www.nytimes.com/2019/09/30/opinion/climate-change.html.

SAGols, Lizbeth. (2011). "El tabú de la sobrepoblación y la ética ambiental". Theoría. Revista del Colegio de Filosofía, (23), 45-58. https://doi.org/10.22201/ ffyl.16656415p.2011.23.371.

SAGOLS, Lizbeth. (2014). La ética ante la crisis ecológica. México: Fontamara; UNAM-PUB.

Salazar Ortiz, Víctor Hugo. (2018). Una visión pragmática de la ética ambiental. México: Universidad Autónoma de Aguascalientes.

Schifter, Isaac; González-Macías, Carmen. (2005). La tierra tiene fiebre. México: FCE; SEP; CONACyT; CAB.

Singer, Peter. (1999). Liberación animal. Madrid: Trotta.

Singer, Peter; Mason, J. (2009). Somos lo que comemos. La importancia de los animales que decidimos consumir (Genis Sánchez Barberán. Trad.). Barcelona: Paidós.

TAYlor, Paul. (1989). Respect for nature. A theory of Environmental ethics. Estados Unidos: Princeton University.

Velayos, Carmen. (2008). Ética y cambio climático. Bilbao: Desclée De Brouwer.

Warren, Karen J. (2004). "El poder y la promesa del feminismo ecológico” (Margarita Valdés Trad.). En Margarita Valdés (comp.), Naturaleza y valor. Una aproximación a la ética ambiental. México: FCE; UNAM-IIF. 233-261. 
Werner, Klaus; Weiss, Hans. (2003). El libro negro de las marcas (Alejandra Obermeier y Marino Grynszpan, trads.). Buenos Aires: Editorial Sudamericana.

WWF. (2015). Impactos del cambio climático sobre las especies. Gland, Suiza: WWF Internacional. Recuperado el 19 de junio de 2002 de http://awsassets.wwf.es/ downloads/especies y cambio climatico informe 2015 wwf.pdf? ga= 2.226417306.1478084704.1549131594-929396354.1448035186. 